\title{
Milk intake and carbon dioxide production of piglets determined with the doubly labelled water technique
}

\author{
P. K. Theil ${ }^{1 \dagger}$, N. B. Kristensen ${ }^{1}$, H. Jørgensen ${ }^{1}$, R. Labouriau ${ }^{2}$ and K. Jakobsen ${ }^{1}$ \\ ${ }^{1}$ Department of Animal Health, Welfare and Nutrition, Danish Institute of Agricultural Sciences, Research Centre Foulum, DK-8830 Tjele, Denmark; ${ }^{2}$ Department \\ of Genetics and Biotechnology, Danish Institute of Agricultural Sciences, Research Centre Foulum, DK-8830 Tjele, Denmark
}

(Received 27 June 2006; Accepted 16 January 2007)

The present study was undertaken to study different methodological aspects of quantifying $\mathrm{CO}_{2}$ production and milk intake of suckling piglets using the doubly labelled water (DLW) technique. In total, 37 piglets were enriched intraperitoneally with DLW to study equilibration time of ${ }^{18} \mathrm{O}(\mathrm{n}=3)$, to validate the estimation of milk intake and $\mathrm{CO}_{2}$ production $(\mathrm{n}=10)$ of piglets fed milk replacer and to quantify milk intake and $\mathrm{CO}_{2}$ production of piglets nursed ordinarily by sows $(\mathrm{n}=24)$. Enrichment of ${ }^{18} \mathrm{O}$ in expired air was analysed without any sample preparation, whereas enrichment of ${ }^{18} \mathrm{O}$ in serum was analysed after a minimum step of sample preparation, which included pipetting of the sample, blowing gaseous $\mathrm{CO}_{2}$ into the vial for $3 \mathrm{~s}$ and equilibrating for $24 \mathrm{~h}$. The ${ }^{18} \mathrm{O}$ enrichment of $\mathrm{CO}_{2}$ in expired air was constant within 30-40 min of intraperitoneal injection, suggesting that DLW was equilibrated within the body water by that time. For piglets fed milk replacer, the estimation of the daily $\mathrm{CO}_{2}$ production by the DLW method $\left(64.0 \pm 2.7 / \mathrm{CO}_{2} /\right.$ day) was in agreement with that obtained by respiration trials $\left(64.7 \pm 1.8 / \mathrm{CO}_{2} /\right.$ day). Furthermore, the intake of milk replacer $\left(891 \pm 63 \mathrm{~g} /\right.$ day) determined by deuterium oxide $\left(\mathrm{D}_{2} \mathrm{O}\right)$ dilution was similar in magnitude to that found by weighing the milk disappearance $(910 \pm 58 \mathrm{~g} /$ day). The milk intake of piglets fed milk replacer was comparable with that of sucking piglets, but sucking piglets had a remarkably higher $\mathrm{CO}_{2}$ production than artificially reared piglets, which likely was caused by a higher intake of milk solids and a higher activity level. For sucking piglets, the daily $\mathrm{CO}_{2}$ production increased curvilinearly with increasing live weight (LW) in $\mathrm{kg}$ : piglet $\mathrm{CO}_{2}$ production $(I /$ day $)=25.75 \times L W-1.01 \times L W^{2}$. In conclusion, ${ }^{18} \mathrm{O}$ equilibrates fast within the body water pool when administered intraperitoneally, and the accuracy of assessing milk intake and rate of $\mathrm{CO}_{2}$ production using the DLW technique is promising. Assessment of excess enrichment of ${ }^{18} \mathrm{O}$ in serum proved to be robust. Finally, the $\mathrm{CO}_{2}$ production of piglets fed milk replacer differs considerably from that of sucking piglets.

Keywords: doubly labelled water, energy metabolism, heat production, milk intake, sucking piglets

\section{Introduction}

Quantitative studies on energy metabolism of sucking piglets are scarce, most likely because of difficulties in deriving reliable estimates of piglet milk intake, digestibility and metabolisability coefficients of ingested sow milk and of heat production (HE) of sucking piglets. In livestock animals, HE is preferably measured by indirect calorimetry because this method allows repeated measurements (Aguilera and Prieto, 1986). However, the technique implies that the sucking piglets and the sow must be kept together in a respiration chamber to allow the piglets to stimulate/ maintain milk production of the sow and to avoid stress of the sow and her litter. However, respiration trials are pro-

† E-mail: Peter.Theil@agrsci.dk blematic because both the piglets and the sow contribute to the gas exchange (Jakobsen et al., 2005). Different approaches have been proposed to evaluate the HE of lactating animals and sucking offspring in pigs and mink (Verstegen et al., 1985; Noblet and Etienne, 1987; Fink et al., 2003). The use of the doubly labelled water (DLW) technique to derive $\mathrm{HE}$ of sucking piglets is an elegant way of overcoming this problem (Jequier and Schutz, 1988), because the DLW technique concomitantly allows estimation of piglet milk intake by the dilution of deuterium oxide $\left(D_{2} 0\right)$ and piglet HE (Ritz et al., 1994). Furthermore, if all piglets are enriched with DLW, the total litter HE and the sow milk production can be quantified. Hence, the DLW method applied on piglets is, in combination with respiration experiments and collection trials, a useful technique when studying quantitative energy metabolism of the 
lactating sow. The DLW technique is ideal because it imposes a minimum of stress on the sow and piglets during the recording period (Pettigrew et al., 1985). However, assumptions and calculations must be made according to species and live weight (LW) of the animals (Speakman, 1997). Three experiments were carried out to test (1) the equilibration time of ${ }^{18} \mathrm{O}$ in 2-week-old piglets enriched intraperitoneally with DLW, (2) to analyse ${ }^{18} 0$ enrichment in piglet serum with a minimum of sample preparation and subsequent validation of the estimation of $\mathrm{CO}_{2}$ production (using DLW technique) and milk intake (using the $D_{2} O$ dilution technique) in piglets fed milk replacer, respectively, and (3) to quantify the $\mathrm{CO}_{2}$ production and milk intake of piglets nursed by sows. The overall aim of the project was to quantify the energy metabolism of the lactating sow and her piglets when their HE was measured in respiration chambers.

\section{Material and methods}

\section{Isotopic enrichment and blood sampling}

Piglets were fasted for $2 \mathrm{~h}$ before an initial blood sample was collected, thereby allowing determination of the background levels of $\mathrm{D}_{2} \mathrm{O}$ and $\mathrm{H}_{2}{ }^{18} \mathrm{O}$. A single intraperitoneal injection of $0.5 \mathrm{ml} / \mathrm{kg} \mathrm{LW}$ was given to piglets. The DLW was a mix of two-thirds of $97 \mathrm{at} \% \mathrm{H}_{2}{ }^{18} \mathrm{O}$ (Isotech, the Netherlands) and one-third of $99.9 \% \mathrm{D}_{2} \mathrm{O}$ (Cambridge Isotopic Laboratories Inc., Andover, MA, USA). Based on results obtained from Experiment 1 in the present paper, a second blood sample was drawn $1 \mathrm{~h}$ after DLW enrichment to determine the initial body water pool of each piglet. A third blood sample was drawn 3 days later to determine the milk intake and $\mathrm{CO}_{2}$ production within that period. Blood samples were obtained from the jugular vein using hypodermic needles $(1.2 \times 40 \mathrm{~mm})$ and $5 \mathrm{ml}$ vacutainers for serum collection (Hemograd Z, Becton Dickinson, Meyland, France). Vacutainers with blood were kept at room temperature until blood was clotted (approximately $2 \mathrm{~h}$ ), after which they were centrifuged $\left(1558 \times \mathbf{g}, 25 \mathrm{~min}, 5^{\circ} \mathrm{C}\right)$. In order to avoid equilibration of ${ }^{18} \mathrm{O}$ with atmospheric $\mathrm{CO}_{2}$, serum was sealed in glass ampoules and then stored at $-18^{\circ} \mathrm{C}$ until analysis. Blood and biopsy sampling, housing and rearing were in compliance with Danish laws and regulations for the humane care and use of animals in research (The Danish Ministry of Justice, Animal Testing Act [Consolidation Act No. 726 of 9 September 1993 as amended by Act No. 1081 of 20 December 1995]). Furthermore, the Danish Animal Experimentation Inspectorate approved the study protocols and supervised the experiment.

\section{Experiment 1: breath test}

The purpose of the first experiment was to evaluate the time required for the DLW to equilibrate with body water of the piglets, based on ${ }^{18} \mathrm{O}$ enrichment of $\mathrm{CO}_{2}$ in expired air (referred to as breath test). Three sucking piglets (Yorkshire $\times$ Danish Landrace/Yorkshire) were enriched with DLW on day 10 of lactation and their LWs were 5.67, 5.11 and $4.00 \mathrm{~kg}$, respectively. Immediately after DLW enrichment, the piglets were placed individually in small open-air circuit respiration chambers (volume of $30 \mathrm{l}$ ) for $3 \mathrm{~h}$. Samples of outgoing air was collected every second minute in $10 \mathrm{ml}$ vacutainers and ${ }^{18} \mathrm{O}$ enrichment of $\mathrm{CO}_{2}$ in expired air was analysed without any sample preparation. If the piglet urinated, the urine was removed instantaneously to avoid flux of ${ }^{18} \mathrm{O}$ from urinary water to gaseous $\mathrm{CO}_{2}$ within the chamber. The time required to reach equilibration of DLW was evaluated as the time from piglet enrichment with DLW to the attainment of a constant level of ${ }^{18} \mathrm{O}$ enrichment in expired air.

\section{Experiment 2: validation study}

The second experiment was carried out to test the analysis of ${ }^{18} \mathrm{O}$ enrichment with a minimum of sample preparation and to validate the estimation of $\mathrm{CO}_{2}$ production and milk intake of piglets fed milk replacer using the DLW and the $\mathrm{D}_{2} \mathrm{O}$ dilution techniques, respectively. Ten sucking piglets (approximately 1 week old) were removed from the sow and fed with milk replacer until 'weaning' at day 28. The piglets were fed a milk replacer every hour from 0300 to $2300 \mathrm{~h}$ with an artificial sow (PigOline, Boss produkter A/S, Ulstrup, Denmark), capable of feeding 1, 2, 3 or 4 piglets individually. The milk replacer used was a commercial mixture (Milky-farm; Nukamel Olen, Belgium), and was mixed twice daily ( $150 \mathrm{~g}$ Milky-farm: $1000 \mathrm{~g}$ of water). Four groups of piglets (one group with four piglets, three groups with two piglets each) were housed in respiration chambers. To minimise stress, piglets within a group were separated only by wire mesh so that they could hear and see each other and lie down in close proximity. The temperature was kept at $27 \pm 0.4^{\circ} \mathrm{C}$, and the relative humidity was maintained at $64 \pm 1.3 \%$. The $\mathrm{CO}_{2}$ production was measured daily on a group basis for $22 \mathrm{~h}$ in respiration chambers, as described by Jørgensen et al. (1996). In addition, the piglets were enriched intraperitoneally with $0.5 \mathrm{~g} \mathrm{DLW} / \mathrm{kg} \mathrm{LW}$ at approximately 10 days of age to determine the rate of $\mathrm{CO}_{2}$ production during a 3-day period. The mean $\mathrm{CO}_{2}$ productions within a group measured by respiration trials and by the DLW technique were compared to evaluate the accuracy of the DLW method ( $n=4$ groups) when calculated according to a one-pool model (Speakman, 1997). Furthermore, the dilution rate of $D_{2} O$ was used to derive the water intake of individual piglets. A representative milk sample was collected throughout a 24-h period and chemical analysis of dry matter (DM), protein, fat, lactose and ash allowed to convert water intake of piglets to milk intake. To validate this technique, the daily amount of milk supplied to the group of piglets was recorded, and control weighing of milk delivered to each piglet was performed daily before and after each respiration trial to estimate the individual allotment. The milk disappearance from the artificial sow and the milk intake were compared on an individual basis ( $n=10$ piglets) to evaluate the accuracy of the $\mathrm{D}_{2} \mathrm{O}$ dilution technique. 
Experiment 3: sucking piglets

Eight LY-sows (Danish Landrace $\times$ Yorkshire) and their second parity litters were used as of parturition to quantify the energy metabolism during lactation (Theil et al., 2004). Lactating sows were fed according to Danish recommendations (Danielsen, 1988) and had ad libitum access to a water nipple, whereas piglets had no access to water. Hence, sow milk and metabolically produced water were assumed to be the only sources of water supply to piglets. During two balance periods (days 10-13 and days 17-20), lactating sows were kept in metabolism cages in respiration chambers with their piglets so that milk production was maintained. An adjacent metabolism cage allowed the piglets to escape from the sow when laying down and this cage offered a place for the piglets to urinate and defaecate in one end and to sleep on a rubber mat in the other end. A heating lamp supplied heat to the piglets when they were in pens and in metabolism cages. Milk samples were taken from the sows at the end of each balance period to obtain the chemical composition of sow milk. Milk samples were obtained from three or four random mammary glands by hand-milking the sows after intravenous injection of $10 \mathrm{IU}(1 \mathrm{ml})$ of oxytocin (Løvens Kemiske Fabrik, Ballerup, Denmark) in an ear vein. Milk was filtered through cheesecloth to eliminate dust and scales, and was stored at $-18^{\circ} \mathrm{C}$ until analysis. Piglets were weighed upon entering and leaving the metabolism cages (when blood samples were drawn). Since the costs of DLW (especially ${ }^{18} 0$ water) are significant, only three piglets per litter were enriched with DLW. In a previous study, we showed that determination of milk intake of three sucking piglets per litter was sufficient to estimate the milk intake of the whole litter and thereby the milk production of the sow (Theil et al., 2002). In four of eight litters, piglets that were not enriched with DLW were labelled with $D_{2} 0$ to determine milk intake.

\section{Analyses}

The atomic fraction (AF) of deuterium in water hydrogen was measured in serum ultrafiltrate as described by Theil et al. (2002). In Experiment 1, the ${ }^{18} 0$ enrichment was analysed as the delta $46 / 44 \mathrm{~m} / \mathrm{z}$ value in $\mathrm{CO}_{2}$ in expired air without any sample preparation (analysed by John Speakman, Aberdeen, Batch \#240). In Experiments 2 and 3, the ${ }^{18} \mathrm{O}$ enrichment was measured in serum water, after transferring $50 \mu \mathrm{l}$ of serum into a $1.5 \mathrm{ml}$ glass vial. The vial was filled with gaseous $\mathrm{CO}_{2}$ by blowing $99.9 \% \mathrm{CO}_{2}$ into the vial for $3 \mathrm{~s}$ (flow rate of $10-15 \mathrm{ml} / \mathrm{s}$ ) and was immediately closed by a rubber lid. Initial tests revealed that ${ }^{18} \mathrm{O}$ enrichment was constant when amount of serum in vials exceeded $30 \mu \mathrm{l}$, indicating that ${ }^{18} \mathrm{O}$ in serum water was in great excess compared with ${ }^{18} \mathrm{O}$ molecules in gaseous $\mathrm{CO}_{2}$. The ${ }^{18} \mathrm{O}$ in serum was allowed to equilibrate with gaseous $\mathrm{CO}_{2}$ for $24 \mathrm{~h}$ at room temperature. The $46 / 44(\mathrm{~m} / \mathrm{z})$ ratio was measured against a working standard gas by gas chromatography/isotope ratio MS (Delta S; Finnigan MAT, Bremen, Germany).
Milk samples were analysed for DM, ash, fat, lactose and total nitrogen, and serum was analysed for DM content. DM and ash were determined according to the Association of Official Analytical Chemists (1990). Protein $(\mathrm{N} \times 6.38)$ was measured by the Kjeldahl method using a Kjell-foss 16200 autoanalyser (Foss Electric, Hillerød, Denmark). Fat was determined after hydrolysis with hydrochloric acid and extraction with diethyl ether (Stoldt, 1952). Lactose was determined using a spectrophotometric method (Beutler, 1984).

\section{Calculations and statistics}

Isotope dilution using both $\mathrm{D}_{2} \mathrm{O}$ and ${ }^{18} \mathrm{O}$ can be used to derive estimates of the total body water of piglets. The $D_{2} \mathrm{O}$ enrichment was quantified absolutely as an atomic fraction of ${ }^{2} \mathrm{H}$ relative to ${ }^{1} \mathrm{H}$ in serum ultrafiltrate, as described by Theil et al. (2002). In contrast, the determination of ${ }^{18} \mathrm{O}$ enrichment is more problematic, because an $\mathrm{m} / \mathrm{z}$ ratio of $46 /$ 44 can be obtained not only by a single ${ }^{18} \mathrm{O}$ atom in $\mathrm{CO}_{2}$ but also by two ${ }^{17} \mathrm{O}$ atoms or by one ${ }^{13} \mathrm{C}$ and one ${ }^{17} \mathrm{O}$ atom in combination with the most abundant isotopes $\left({ }^{12} \mathrm{C}\right.$ and $\left.{ }^{16} 0\right)$. Therefore, the DLW injectate was diluted serially with background pig serum to establish a calibration curve. By using the intercept and slope from the calibration curve (Figure 1), the measured $\mathrm{m} / \mathrm{z} 46 / 44$ value of unknown samples was converted to an arbitrary fraction of the injectate, which was equivalent to the ${ }^{18} 0$ enrichment over baseline (EOB) of pig serum. Finally, the DM content of serum was analysed $(7.00 \%$ - see Results) and a factor of 0.93 was used to convert the ${ }^{18} \mathrm{O}$ EOB in serum into ${ }^{18} \mathrm{O}$ EOB of water:

$$
\begin{aligned}
{ }^{18} \mathrm{O} \text { EOB of water }(\text { with no unit })= & (46 / 44 \text { signal }- \text { intercept }) / \\
& \left(\text { slope } \times 10^{6} \times 0.93\right)
\end{aligned}
$$

where $46 / 44$ signal is the measured $\mathrm{m} / \mathrm{z}$ ratio of ${ }^{18} 0$ enrichment in serum of unknown samples, intercept and slope was regression parameters from the calibration curve,

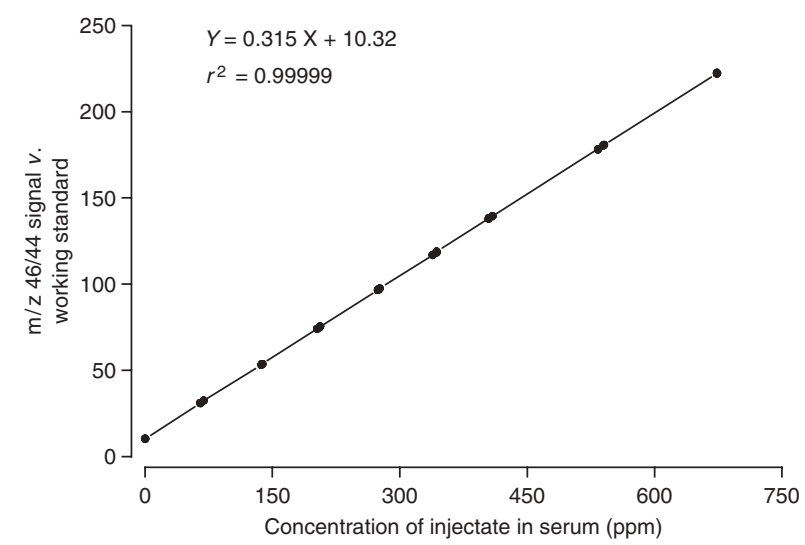

Figure 1 Calibration curve analysed to calculate ${ }^{18} 0$ enrichment over baseline for unknown samples, as described in Equation 1. The most concentrated standard solution in the calibration curve had a concentration similar to the level observed in piglets after DLW was equilibrated, i.e. $1 \mathrm{~h}$ after DLW injection. 
the factor $10^{6}$ was used to convert p.p.m. into atomic fraction of the injectate and the factor 0.93 was applied to account for the DM fraction of serum.

The ${ }^{18} \mathrm{O}$ EOB in the first blood sample after enrichment was used to estimate the body water pool in moles $\left(N_{0 \text {-ini }}\right)$ and the body water fraction $\left(\mathrm{BWF}_{\text {ini }}\right)$ at enrichment:

$$
\begin{aligned}
& N_{\text {O-ini }} \text { moles }=m_{\text {inj }} /\left({ }^{18} \mathrm{O} \text { EOB of water } \times \mathrm{M}_{\mathrm{H}_{2} \mathrm{O}}\right), \\
& \mathrm{BWF}_{\text {ini }} \text { (with no unit) }=N_{\mathrm{O} \text {-ini }} \times 0.001 \times \mathrm{M}_{\mathrm{H}_{2} \mathrm{O}} / \mathrm{LW},
\end{aligned}
$$

where $m_{\text {inj }}$ is the mass of injectate (inj) in $g_{1}{ }^{18} 0$ EOB is the ${ }^{18} \mathrm{O}$ enrichment over baseline in the blood sample drawn $1 \mathrm{~h}$ post injection, 0.001 is used to convert $\mathrm{g}$ of body water into $\mathrm{kg}, \mathrm{M}_{\mathrm{H}_{2} \mathrm{O}}$ is the molecular weight of water $(18.01499 \mathrm{~g} /$ $\mathrm{mol})$, and LW is the live weight of the piglet in $\mathrm{kg}$.

According to our previous study (Theil et al., 2002), the BWF of sucking piglets decreases curvilinearly with increasing LW and may be predicted by

$$
\begin{aligned}
\left.\mathrm{BWF}_{\text {pred }} \text { (with no unit }\right)= & 0.825-0.130 \times \log \mathrm{E}(\mathrm{LW}) \\
& +0.026 \times(\log \mathrm{E}(\mathrm{LW}))^{2}
\end{aligned}
$$

where LW of piglets is in $\mathrm{kg}$. Hence, the total body water of piglets at subsequent blood samples ( 3 days after enrichment) was found by scaling according to Equation 4. The deviation between the initial BWF $\left(\mathrm{BWF}_{\text {ini }}\right)$ and the predicted $B W F\left(B W F_{\text {pred }}\right.$ ) was assumed to persist throughout the study, i.e. a lean piglet at enrichment was assumed to remain leaner than the average piglet during the 3-day period. Hence, the BWF (BWF end) and body water pool $\left(Q_{\text {-end }}\right)$ after 3 days of suckling were determined as follows:

$$
\begin{aligned}
\mathrm{BWF}_{\text {end }}= & 0.825-0.130 \times \log \mathrm{E}(\mathrm{LW})+0.026 \times(\log \mathrm{E}(\mathrm{LW}))^{2} \\
& +\left(\mathrm{BWF}_{\text {ini }}-\mathrm{BWF}_{\text {pred }}\right), \\
Q_{0 \text {-end }} \text { moles } & =\mathrm{BWF}_{\text {end }} \times \mathrm{LW} \times 1000 / \mathrm{M}_{\mathrm{H}_{2} \mathrm{O}},
\end{aligned}
$$

where 1000 was used to convert $\mathrm{kg}$ of body water into $\mathrm{g}$. The dilution rates of $\mathrm{D}_{2} \mathrm{O}\left(k_{\mathrm{D}}\right)$ and ${ }^{18} \mathrm{O}\left(k_{0}\right)$ were found by

$$
\begin{gathered}
k_{\mathrm{D}}=\left(\log \mathrm{E}\left(\mathrm{D}_{2} \mathrm{OAF_{1 }}\right)-\log \mathrm{E}\left(\mathrm{D}_{2} \mathrm{OAF} \mathrm{F}_{2}\right)\right) / \Delta t, \\
k_{0}=\left(\log \mathrm{E}\left({ }^{18} \mathrm{OEOB}_{1}\right)-\log \mathrm{E}\left({ }^{18} \mathrm{O} \mathrm{EOB}_{2}\right)\right) / \Delta t,
\end{gathered}
$$

where $D_{2} O A F_{1}$ and $D_{2} O A F_{2}$ are the atomic fractions of deuterium in two consecutive blood samples after enrichment. Respectively, ${ }^{18} \mathrm{O} \mathrm{EOB}_{1}$ and ${ }^{18} \mathrm{O} \mathrm{EOB}_{2}$ are the enrichments over baseline on ${ }^{18} \mathrm{O}$ of the same two samples, and $\Delta t$ is the time difference between samples 1 and 2 .

Finally, the $\mathrm{CO}_{2}$ production was calculated according to the single-pool model, proposed by Lifson and McClintock (1966):

$$
\begin{aligned}
r \mathrm{CO}_{2}= & N_{0} \times\left(0.480769 \times k_{0}-0.495769 \times k_{\mathrm{D}}\right) \\
& \times 273.15 \times 0.08205,
\end{aligned}
$$

where $N_{0}$ is the average of the body water pool (in moles) determined initially $\left(Q_{0-\text {-ini }}\right)$ by ${ }^{18} O$ dilution and predicted at the end of the measuring period $\left(Q_{0 \text {-end }}\right), k_{0}$ is the fractional turn-over rate of ${ }^{18} \mathrm{O}$ and $k_{\mathrm{D}}$ is the fractional turnover rate of $\mathrm{D}_{2} \mathrm{O}$, the two constants 273.15 and 0.08205 are used to convert the $\mathrm{CO}_{2}$ production into litres at standard conditions (i.e. corrected to dry air at constant temperature and pressure).

The milk intake of piglets was assessed by determining the fractional water turn-over and the body water pool using the $\mathrm{D}_{2} \mathrm{O}$ dilution technique. The water intake was converted to milk intake based on the chemical composition of milk replacer (experiment 2) or sow milk (experiment 3 ) and by taking into account the metabolically produced water from nutrient oxidation. Milk intake was calculated as described by Coward et al. (1982)

$$
\begin{aligned}
& \text { Milk intake (g per piglet per day) } \\
& =\frac{\text { water turn-over }+ \text { potential metabolic water stored }}{\text { potential water fraction of milk }},
\end{aligned}
$$

where water turnover was calculated as the fractional water turnover multiplied by the total body water; potential water fraction of milk was calculated based on the analysed chemical composition of milk and potential metabolic water stored was calculated by assuming that retention of DM in piglets was equal for deposition of both fat and protein. The $\mathrm{D}_{2} \mathrm{O}$ dilution technique used to assess piglet milk intake, the chemical analyses of milk components, the underlying assumptions of the technique and calculations are described in detail by Theil et al. (2002).

The following normal mixed model (MIXED procedure of SAS (Littell et al., 1996) was used to describe variables related to piglet performance (Table 2):

$$
Y_{s p i j}=\mu+\alpha_{i}+\beta_{j}+(\alpha \times \beta)_{i j}+S_{s}+P(S)_{p s}+\varepsilon_{s p i j},
$$

where $Y_{\text {spij }}$ represents the variables related to piglet performance for the Pth piglet $(p=1,2, \ldots 13)$ of the Sth sow $(s=1,2,3,4)$ at the ith period $(i=1,2)$ fed with the jth milk source $\left(j=\right.$ milk replacer, sow milk). Furthermore, $\mu_{1} \alpha_{i}$ and $\beta_{j}$ are the grand mean, and the fixed effects related to the factor representing period and milk source, respectively, and $(\alpha \times \beta)_{i j}$ represents the interactions between the two fixed effects. The random components related to sow $\left(S_{s}\right)$ and piglet nested within sow $P(S)_{\mathrm{ps}}$ and the residual error component $\left(\varepsilon_{\text {spij }}\right)$ were assumed to be independent and normally distributed and their expectations were assumed to be zero.

\section{Results}

\section{Breath test}

The enrichment of ${ }^{18} 0$ in expired air increased immediately after DLW was injected intraperitoneally, peaked approximately 15 min later, and then dropped to a stable plateau after $30-40 \mathrm{~min}$. The dynamic changes of ${ }^{18} \mathrm{O}$ enrichment of expired air during the first $3 \mathrm{~h}$ after DLW injection are shown for one of three piglets (Figure 2).

\section{Validation study}

The DM content of piglet serum was $7.00 \pm 0.12 \%$. Dilution of serum from DLW-enriched piglets with serum harvested from a pig not enriched with DLW yielded a perfect linear relationship between the relative (arbitrary) content and the 


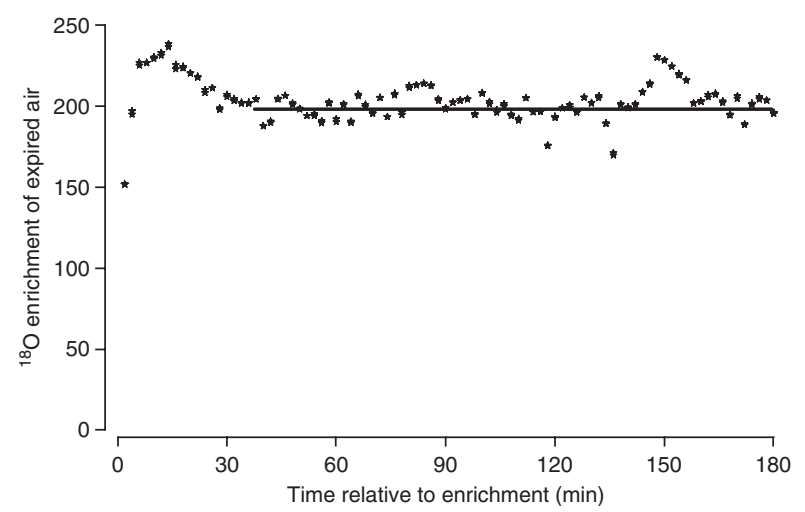

Figure 2 Test of equilibration time of ${ }^{18} 0$ water in piglets. Samples of expired air (breath test) were collected every other minute for $3 \mathrm{~h}$, and ${ }^{18} \mathrm{O}$ enrichment was analysed.

Table 1 Chemical composition (mean \pm s.e.) of milk replacer $(\mathrm{n}=2)$ and sow milk $(\mathrm{n}=16)$ from experimental sows in weeks 2 and 3 of lactation

\begin{tabular}{lcc}
\hline \hline & $\begin{array}{c}\text { Milk replacer } \\
\text { (Exp. 2) }\end{array}$ & $\begin{array}{c}\text { Sow milk } \\
\text { (Exp. 3) }^{\dagger}\end{array}$ \\
\hline Dry matter (DM) (g/100 g milk) & $12.7^{\mathrm{b}} \pm 0.01$ & $17.6^{\mathrm{a}} \pm 0.3$ \\
Protein $(6.38 \times \mathrm{N})(\mathrm{g} / 100 \mathrm{~g} \mathrm{DM})$ & $23.5^{\mathrm{b}} \pm 0.3$ & $29.7^{\mathrm{a}} \pm 0.7$ \\
Fat $(\mathrm{g} / 100 \mathrm{~g} \mathrm{DM})$ & $25.7^{\mathrm{b}} \pm 2.8$ & $37.4^{\mathrm{a}} \pm 1.1$ \\
Lactose $(\mathrm{g} / 100 \mathrm{~g}$ DM) & $32.7 \pm 2.3$ & $30.9 \pm 0.9$ \\
Non-lactose carbohydrate & $10.7 \pm 0.4$ & - \\
(g/100 g DM) & $10.4^{\mathrm{a}} \pm 0.2$ & $4.7^{\mathrm{b}} \pm 0.1$ \\
Ash $(\mathrm{g} / 100 \mathrm{~g} \mathrm{DM})$ & $21.69^{\mathrm{b}} \pm 0.19$ & $25.52^{\mathrm{a}} \pm 0.19$ \\
Gross energy (MJ/kg DM) & $0.948^{\mathrm{a}} \pm 0.001$ & $0.942^{\mathrm{b}} \pm 0.001$ \\
Potential water fraction & \\
\hline \hline
\end{tabular}

$\overline{\mathrm{a}, \mathrm{b}}$ In a row indicate significant differences between milk replacer and sow milk based on Wald's test.

${ }^{\dagger}$ No difference was found in chemical composition of sow milk between weeks 2 and 3 of lactation.

FPotential water fraction is the water content of milk (milk replacer or sow milk) corrected for metabolic water that would be produced if all the digested dry matter was oxidised. The digestibilities of protein, fat, nonlactose and lactose were assumed to be $0.88,0.98,1.00$ and 1.00 , respectively. The analysed dry matter content was corrected to $100 \%$ before calculating the potential water fraction, as reported by Theil et al. (2002). analysed ${ }^{18} 0$ enrichment over baseline (Figure 1). The ${ }^{18} 0$ excess enrichment of piglets in background samples (i.e. pre-injection) was $1.2 \pm 0.9$ p.p.m. (range -2.3 to 6.8 p.p.m.), whereas the excess enrichment after steady state was attained at $679 \pm 21$ p.p.m. (range 555-773 p.p.m.).

The milk replacer contained $12.7 \% \mathrm{DM}$ and on a DM basis, the protein, fat, lactose, non-lactose carbohydrates and ash contents amounted to $22.3 \%, 25.0 \%, 31.9 \%$, $10.4 \%$ and $10.3 \%$, respectively (Table 1 ). The energy content was $21.69 \mathrm{MJ} / \mathrm{kg} \mathrm{DM}$ and the potential water fraction of milk was 0.948 .

The 10 piglets reared artificially with milk replacer ingested on average $910 \pm 58 \mathrm{~g} /$ day as evaluated by the rate of milk disappearance. Based on the $D_{2} 0$ dilution technique, the milk intake was estimated to be $891 \pm 63 \mathrm{~g} /$ day (Table 2). The fitted linear regression between estimated milk intake ( $Y$-axis) and weighed milk disappearance ( $X$-axis) was $Y=0.98 \times X$ if using a no intercept model $(P=0.25$ for no intercept; Figure 3). On an individual basis, the difference between weighed milk disappearance and milk intake estimated by $D_{2} \mathrm{O}$ dilution was in the range of -24 to $+90 \mathrm{~g} /$ day. Artificially reared piglets were housed in four groups in respiration chambers. The daily rate of $\mathrm{CO}_{2}$ production, determined by gas exchange, per piglet in the groups averaged $64.7 \pm 1.8 \mathrm{l} /$ day per piglet. In accordance, the daily rate of $\mathrm{CO}_{2}$ production, as assessed by the DLW method, amounted to $64.0 \pm 2.7 \mathrm{l} /$ day per piglet. The fitted regression using a no intercept model $(P=0.14$ for no intercept) between $\mathrm{CO}_{2}$ production assessed by the DLW method ( $Y$-axis) and by indirect calorimetry ( $X$-axis) was close to a perfect fit $(Y=0.99 \times X)$.

\section{Sucking piglets}

Sow milk contained $17.6 \%$ DM and on a DM basis, the protein, fat, lactose and ash contents were $28.9 \%, 36.4 \%$, $30.1 \%$ and $4.6 \%$, respectively (Table 2 ). The gross energy content of milk was $25.52 \mathrm{MJ} / \mathrm{kg} \mathrm{DM}$, and the potential water fraction was 0.942 .

Table 2 Data on artificially reared piglets and sucking piglets on days 10-13 and days 17-20 post partum

\begin{tabular}{|c|c|c|c|c|}
\hline \multirow[b]{2}{*}{ Days post partum } & \multicolumn{2}{|c|}{ Artificially reared piglets (Exp. 2) } & \multicolumn{2}{|c|}{ Sucking piglets (Exp. 3) } \\
\hline & $10-13$ & $17-20$ & $10-13$ & $17-20$ \\
\hline No. of piglets & 10 & 10 & 47 & 47 \\
\hline Mean live weight $(\mathrm{g})$ & $3.02^{c} \pm 0.36$ & $3.96^{\mathrm{b}} \pm 0.36$ & $3.32^{b c} \pm 0.13$ & $4.82^{a} \pm 0.13$ \\
\hline Live-weight gain (g/day) & $138^{\mathrm{b}} \pm 26$ & $154^{b} \pm 26$ & $171^{b} \pm 9$ & $219^{a} \pm 9$ \\
\hline Body water $(\%)$ & $77.6^{\mathrm{a}} \pm 1.0$ & $75.8^{b} \pm 1.0$ & $73.6^{c} \pm 0.4$ & $71.5^{\mathrm{d}} \pm 0.4$ \\
\hline Milk intake (g/day) ${ }^{\dagger}$ & $891^{b c} \pm 101$ & $1182^{a} \pm 101$ & $864^{c} \pm 46$ & $1055^{a b} \pm 46$ \\
\hline Energy intake (MJ/day) & $2.46^{\mathrm{c}} \pm 0.43$ & $3.26^{b} \pm 0.43$ & $3.88^{\mathrm{b}} \pm 0.20$ & $4.74^{\mathrm{a}} \pm 0.20$ \\
\hline $\mathrm{CO}_{2}$ production $(\mathrm{I} / \text { day })^{\ddagger}$ & $64.0^{b} \pm 2.7$ & - & $93.7^{\mathrm{a}} \pm 5.1$ & - \\
\hline
\end{tabular}

a,b,c,d Means with superscripts in a row indicates a significant effect of period (comparison within an experiment) or a significant effect of milk source (comparison between experiments).

${ }^{t}$ Determined by the $D_{2} O$ dilution technique.

'Determined by the DLW method ( $n=24$ piglets in experiment 3 for this parameter). 


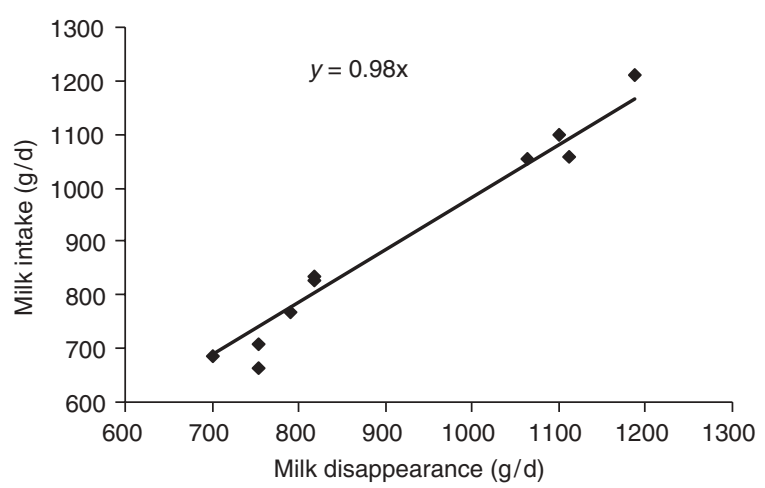

Figure 3 Validation of piglet milk intake determined by the $D_{2} 0$ dilution technique and by weighing the amount of milk allotted to individual piglets (milk disappearance) on days 10-13 post partum. Piglets were fed milk replacer as of day 8 post partum.

LW $(P<0.001)$, LW gain $(P<0.001)$, milk intake $(P<0.01)$ and energy intake of sucking piglets increased $(P<0.01)$ from days 10 to 13 to days 17 to 20 , whereas body water percentage decreased with increasing age $(P<0.01$; Table 2). The average $\mathrm{CO}_{2}$ production of the three median piglets according to LW within litters ( $n=24)$ was 93.7 l/day. For sucking piglets, the following regression between live weight $(\mathrm{LW}, \mathrm{kg})$ and daily $\mathrm{CO}_{2}$ production was found:

Piglet $\mathrm{CO}_{2}$ production $(\mathrm{l} /$ day $)=25.75 \times \mathrm{LW}-1.01 \times(\mathrm{LW})^{2}$.

\section{Discussion}

The fast stabilisation of ${ }^{18} 0$ enrichment in expired air showed that ${ }^{18} 0$ was rapidly transported from the intraperitoneal cavity and distributed throughout the entire body of the piglet via the blood. After $15 \mathrm{~min}$, the enrichment peaked and then dropped quickly to a steady-state level. This pattern was probably caused by an initial equilibration of ${ }^{18} \mathrm{O}$ with blood and intercellular water, whereas it obviously takes longer (approximately $40 \mathrm{~min}$ ) for the ${ }^{18} 0$ to equilibrate with intracellular water. The result is comparable with the 20 and $40 \mathrm{~min}$ required for $\mathrm{D}_{2} \mathrm{O}$ to equilibrate after intravenous and intramuscular injections, respectively (Rudolph et al., 1988).

The serial dilutions of DLW-enriched serum yielded a perfect linear response in ${ }^{18} \mathrm{O}$ enrichment over baseline. To convert the ${ }^{18} \mathrm{O}$ abundance in serum into ${ }^{18} \mathrm{O}$ abundance in water, the water content of piglet serum $(93.0 \%)$ was measured. When the ${ }^{18} \mathrm{O}$ abundance was expressed as enrichment over baseline (i.e. excess enrichment) and corrected for DM content, values were essentially 0 p.p.m. in blood samples drawn prior to enrichment. Hence, the presented approach proved to be a robust and precise technique and required only a minimum of sample preparation. Another advantage with the presented method is that it avoids correction for ${ }^{17} \mathrm{O}$ and ${ }^{13} \mathrm{C}$ abundances in piglet serum. The analysis of ${ }^{18} \mathrm{O}$ enrichment in serial dilutions using serum was similar to the approach used to measure $D_{2} \mathrm{O}$ enrichment of piglet serum (Pluske et al., 1997).
The milk replacer used in the validation study differed chemically from the reported composition of sow milk (Darragh and Moughan, 1998; Theil et al., 2004): When the milk replacer was mixed according to the manufacturer's recommendations, it contained only $12.7 \% \mathrm{DM}$, whereas sow milk contains $18-19 \%$. Furthermore, the milk replacer had lower contents of both protein and fat and higher ash content than sow milk (Table 1). In contrast to sow milk, the milk replacer contained carbohydrates other than lactose which constituted approximately $10 \%$ of the DM fraction. As a consequence of the altered chemical composition, the energy content of the milk replacer was lower than that reported for sow milk (21.69 v. $25.52 \mathrm{MJ} / \mathrm{kg}$ DM, respectively), and the piglets fed milk replacer likely had a lower fat deposition as indicated by the higher BWF on days 17-20. The lower fat retention may explain for the lower growth performance after weaning observed for piglets fed milk replacer before weaning (Wolter et al., 2002).

Based on Equation 10, it is evident that characteristics related both to piglets (water turn-over and potential metabolic water stored) and to the sow (potential water fraction of milk) are important for assessing the milk intake of piglets based on the $\mathrm{D}_{2} \mathrm{O}$ dilution technique. However, in spite of the different chemical composition (milk replacer $v$. sow milk), the potential water fraction of the milk replacer was comparable with that of sow milk and indicates that variations in chemical composition of milk should have only negligible impact on the potential water fraction of milk. In agreement, we have previously found that the potential water fraction of milk does not change during lactation and does not vary among experiments in spite of differences in chemical composition (Theil et al., 2002 and 2004). For future experiments, we, therefore, suggest that a constant of 0.942 be used as the potential water fraction of sow milk. However, if $\mathrm{D}_{2} \mathrm{O}$ dilution is used to quantify colostrum intake, the potential water fraction is somewhat lower (approximately 0.88 ), because the digestibilities of fat and proteins in colostra are lower than in milk (Devillers et al., 2004).

There was agreement between values for milk intake measured by the $\mathrm{D}_{2} \mathrm{O}$ dilution technique and by weighing milk ingested while artificially fed, the deviation between the two methods amounted to approximately $2 \%$. The discrepancy between the two methods may be caused by an underestimation of the milk intake by the $\mathrm{D}_{2} \mathrm{O}$ dilution technique, or a slight overestimation of the actual milk intake of piglets evaluated by milk disappearance. In favour of the latter explanation, minor amounts of milk was retained in the tubes leading milk replacer into the drinking cup inside the cage and some piglets spilt minor amounts. The present study supports the conclusion of Prawirodigdo et al. (1990) that the $D_{2} 0$ dilution technique predicts the amounts of milk disappearing from artificial nipples with an accuracy of $97.9-100.5 \%$. The $D_{2} 0$ dilution estimates are evidently superior to the weigh-suckle-weigh estimates of sow milk production (Pettigrew et al., 1985; Theil et al., 
2002), due to metabolic and salivary losses and due to disruptions of sow-piglet interactions.

Estimation of $\mathrm{CO}_{2}$ production rate by means of the DLW method depends on whether the water dilution spaces are based only on ${ }^{18} \mathrm{O}$ (one-pool model) or on both $\mathrm{D}_{2} \mathrm{O}$ and ${ }^{18} \mathrm{O}$ (two-pool model). According to Speakman (personal communication), a one-pool model should always be used for animals weighing up to $2 \mathrm{~kg}$, and a two-pool model should always be used for animals weighing $>10 \mathrm{~kg}$. A twopool model is most appropriate for large animals in order to account for ${ }^{18} 0$ incorporation into fat tissue. Accordingly, the present paper suggests that the one-pool model described by Lifson and McClintock (1966) does estimate the $\mathrm{CO}_{2}$ production accurately on a group basis (two piglets in three groups, four in the fourth group), since a fitted regression between $\mathrm{CO}_{2}$ production estimated by the DLW method and that measured by indirect calorimetry yielded a nearly perfect fit (slope $=0.99$ with a no-intercept model). The low BW of sucking piglets and their low fat content in early lactation may explain why the one-pool model was the most appropriate. In contrast to the accuracy, the precision was rather low, indeed the deviation between the two methods was in the range of -8.7 to $6.9 \mathrm{l} / \mathrm{day}$. The DLW method estimated the $\mathrm{CO}_{2}$ production for the four groups within $89.8-114.4 \%$ of that measured by indirect calorimetry. A higher initial ${ }^{18} 0$ enrichment would likely improve the precision of measurement. However, determination of the body water pool at the end of the measuring period will also improve the precision, because the body water pool changes rapidly in pigs (Haggarty et al., 1994) and the water pool greatly affects the derived estimate of $\mathrm{CO}_{2}$ production (Speakman, 1997).

The $\mathrm{CO}_{2}$ production of sucking piglets $(93.7 \mathrm{l} /$ day) on days 10-13 was considerably higher than that of piglets fed milk replacer $(64.0 \mathrm{l} /$ day) most likely due to different activity and feeding levels (piglets fed milk replacer consumed less energy, due to low fat and solid content of the milk replacer). The activity level of sucking piglets was higher compared to that of artificially reared piglets, because sucking piglets spent time and energy fighting for their gland position and stimulating the sow's udder. Another reason for the higher $\mathrm{CO}_{2}$ production observed in sucking piglets is the higher intake of milk energy, which is known to increase $\mathrm{O}_{2}$ consumption (Noblet and Etienne 1987) and, therefore, also increases $\mathrm{CO}_{2}$ production. Noblet and Etienne (1987) measured the gas exchange of sucking piglets between sucking bouts ('resp-suckle-resp' approach) and reported a daily $\mathrm{CO}_{2}$ production of $63.4 \mathrm{I}$ per piglet, which is similar to that found in the present study for artificially reared piglets, but not for the sucking piglets. Initially, we planned to adopt their 'resp-suckle-resp' approach but realised that piglets slept most of the time between the sucking bouts, which, therefore causes an underestimation of the litter $\mathrm{HE}$.

In summary, the DLW method is a useful technique for quantitative studies of nutrient metabolism in sucking piglets and their dam. If $\mathrm{CO}_{2}$ production and milk intake of sucking piglets are assessed by the DLW method, and if these data are combined with measurements of the gas exchange (indirect calorimetry) and with collection of faeces and urine of the lactating sow and her litter, it is possible to quantify the energy and the protein balances of both the lactating sow and her litter.

\section{Acknowledgements}

The present experiment was a part of the Nordic Joint Committee for Agricultural Research (NKJ), Project No. 100 'Stable isotopes in comparative studies of milk production and energy requirement in pigs, mink and foxes', financially supported by The Danish Veterinary and Agricultural Research Council, Grant No. 9701275. The studies with doubly labelled water were supported by a grant from Ellen, Christian and Anders Petersens foundation. The authors wish to thank Professor J. Speakman, University of Aberdeen, Scotland, for analysing ${ }^{18} 0$ enrichment of samples of expired air, Dr Viggo Danielsen and Dr Anne-Helene Tauson for fruitful discussions and for comments on an earlier version of the manuscript and, finally, thanks to Benny Thomasen for practical help.

\section{References}

Aguilera JF and Prieto C 1986. Description and function of an open-circuit respiration plant for pigs and small ruminants and the techniques used to measure energy metabolism. Archives of Animal Nutrition 36, 1009-1018.

Association of Official Analytical Chemists 1990. Official methods of analysis, 15th edition.AOAC, Arlington, VA, USA.

Beutler HO 1984. Lactose and D-galactose. In Methods of enzymatic analysis (ed. HU Bergmeyer and M Grassl), pp.104-112. Verlag Chemie, Weinheim.

Coward WA, Cole TJ, Gerber H, Roberts SB and Fleet I 1982. Water turnover and the measurement of milk intake. Pflugers Archive 393, 344-347.

Danielsen $V$ 1988. Nye energinormer til søer [New recommendations of energy supply to sows]. Hyologisk tidsskrift 8, 27-28.

Darragh AJ and Moughan PJ 1998. The composition of colostrum and milk. In The lactating sow (ed. MWA Verstegen, PJ Moughan and JW Schrama) pp. 3-21. Wageningen Pers, Wageningen.

Devillers N, van Milgen J, Prunier A and Dividich J 2004. Estimation of colostrum intake in the neonatal pig. Animal Science 78, 305-313.

Fink R, Tauson AH, Chwalibog A, Kristensen NB and Wamberg S 2003. Effects of low protein supply on energy metabolism and milk production of the mink (Mustela vison). In Progress in research on energy and protein metabolism (ed. WB Souffrant and CC Metges), pp. 163-166. Wageningen Academic Publishers, The Netherlands, Wageningen.

Haggarty P, Franklin MF, Fuller MF, McGaw BA, Milne E, Duncan G, Christie SL and Smith JS 1994. Validation of the doubly labeled water method in growing pigs. The American Journal of Physiology 267, R1574-R1588.

Jakobsen K, Theil PK and Jørgensen H 2005. Methodological considerations as to quantify nutrient and energy metabolism in lactating sows. Journal of Animal and Feed Sciences 14, 31-47.

Jequier $E$ and Schutz $Y$ 1988. Classical respirometry and the doubly-labelledwater $\left({ }^{2} \mathrm{H}_{2}{ }^{18} \mathrm{O}\right)$ method: appropriate applications of the individual or combined techniques. Proceedings of the Nutrition Society 47, 219-225.

Jørgensen $H$, Zhao XQ and Eggum BO 1996. The influence of dietary fibre and environmental temperature on the development of the gastrointestinal tract, digestibility, degree of fermentation in the hind-gut and energy metabolism in pigs. The British Journal of Nutrition 75, 365-378.

Lifson $\mathrm{N}$ and McClintock R 1966. Theory of use of the turnover rates of body water for measuring energy and material balance. Journal of Theoretical Biology 12, 46-74.

Littell RC, Milliken GA, Stroup WW and Wolfinger RD 1996. SAS (R) System for mixed models. SAS Institute Inc., Cary, NC, USA. 
Theil, Kristensen, Jørgensen, Labouriau and Jakobsen

Noblet J and Etienne M 1987. Body composition, metabolic rate and utilization of milk nutrients in suckling piglets. Reproduction, Nutrition, Development 27, 829-839.

Pettigrew JE, Sower AF, Cornelius SG and Moser RL 1985. A comparison of isotope dilution and weigh-suckle-weigh methods for estimating milk intake by pigs. Canadian Journal of Animal Science 65, 989-992.

Pluske JR, Fenton TW, Lorschy ML, Pettigrew JE, Sower AF and Aherne FX 1997. A modification to the isotope-dilution technique for estimating milk intake of pigs using pig serum. Journal of Animal Science 75, 1279-1283.

Prawirodigdo S, King RH, Dunkin AC and Dove $H$ 1990. Evaluation of techniques for estimating milk production by sows 1. Deuterium oxide dilution method for estimating milk intake by piglets. Asian-Australasian Journal of Animal Science 3, 135-141.

Ritz P, Johnson PG and Coward WA 1994. Measurements of $\mathrm{H}-2$ and 0-18 in body water: analytical considerations and physiological implications. The British Journal of Nutrition 72, 3-12.

Rudolph BC, Stahly TS and Cromwell GL 1988. Estimation of body composition of neonatal pigs via deuterium oxide dilution: validation of technique. Journal of Animal Science 66, 53-61.
Speakman JR 1997. Doubly labelled water. Theory and practice. Chapman \& Hall, London, UK.

Stoldt W 1952. Vorslag zur Vereinheitlichung der Fettbestimmung in Lebensmitteln. Fette und Seifen 54, 206-207.

Theil PK, Nielsen TT, Kristensen NB, Labouriau R, Danielsen V, Lauridsen C and Jakobsen K 2002. Estimation of milk production in lactating sows by determination of deuterated water turnover in three piglets per litter. Acta Agriculturae Scandinavica, Section A 52, 221-232.

Theil PK, Jørgensen $\mathrm{H}$ and Jakobsen $\mathrm{K} 2004$. Energy and protein metabolism in lactating sows fed two levels of dietary fat. Livestock Production Science 89, 265-276.

Verstegen MWA, Mesu J, Van Kempen G and Geerse C 1985. Energy balances of lactating sows in relation to feeding level and stage of lactation. Journal of Animal Science 60, 731-740.

Wolter BF, Ellis M, Corrigan BP and DeDecker JM 2002. The effect of birth weight and feeding of supplemental milk replacer to piglets during lactation on preweaning and postweaning growth performance and carcass characteristics. Journal of Animal Science 80, 301-308. 